\title{
Abstract Submission CAEP Annual Conference May 29-June 2, 2010
}

\section{CALL FOR ABSTRACTS}

CAEP invites all researchers to submit their original clinical, basic or population health research for presentation at the CAEP 2010 Conference in Montréal, Que., May 29-Jun. 2, 2010. The Organizing Committee works hard to ensure the research presentations have a high profile at this meeting, therefore, abstracts should represent original research that has

- not been published or presented at a national (Canadian) scientific meeting; and

- not been previously published in a paper, online journal or book.

All abstracts must be submitted electronically for receipt on or before Monday, Jan. 11, 2010, 2359 MST through the research page on the CAEP website.

\section{INSTRUCTIONS FOR PREPARING ABSTRACTS}

(Note: Failure to follow instructions will result in abstract disqualification.)

Abstracts may be submitted in English or French. The abstract must

- be typed single space, clear and legible;

- be submitted electronically after Nov. 1, 2009. Fill in all mandatory boxes. Do not leave empty fields;

- contain the following headings, underlined and in order: Introduction, Methods, Results, and Conclusion;

- provide the institutional affiliation, city and province of the primary author only.

The text of the abstract should be left-justified, with a maximum length of 300 words. Abbreviations should be kept to a minimum and defined when first used. NOTE: No graphs or tables in any format will be accepted.

\section{ABSTRACT REVIEW PROCESS}

All abstracts will be peer reviewed by at least 3 CAEP abstract reviewers using a standardized evaluation form. The reviewers will be blinded to the authors' name(s) and institutional affiliation(s). Reviewers will not review abstracts from within their own province. Strict conflict of interest declarations will be provided to each reviewer. Abstracts will be selected for oral or poster presentation. Oral presenters will be permitted 10 minutes for their presentation, with 5 minutes for discussion. Posters will be available for viewing in a central location at the Hilton Bonaventure. Notification of acceptance will be transmitted via email no later than Mar. 1, 2010. Consequently, all contact information must be correct at submission. We regret we cannot give notification via telephone. Complete presentation schedules will be posted on the CAEP website (www.caep.ca). Publication of the original abstract in CJEM will be completed once the abstracts are accepted.

\section{CAEP RESIDENT MEMBER ABSTRACT COMPETITION}

CAEP Research Committee will provide travel funding to the top 10 ranked CAEP resident* member abstracts. Residents must be registered in Canadian accredited (CFPC or RCPSC) EM programs or have graduated within the previous year (i.e., July 2009). Residents must be the primary investigator and responsible for the project development, the presenter of the abstract (oral) and the first named author. Fellows (Pediatric Emergency Medicine and others) do not qualify for consideration in this competition unless the research was completed during their EM residency.

*You must have paid your 2010 CAEP membership dues at the time of your abstract submission. 